\title{
Epidemiology and surveillance of methicillin- resistant Staphylococcus aureus in Latin America
}

\begin{abstract}
Surveillance systems monitoring the spread and divergence of methicillin-resistant Staphylococcus aureus (MRSA) strains are critical if preventive and therapeutic measures targeting MRSA infection are to be employed optimally. Surveillance provides information on the spread of MRSA, on the emergence of new strains within hospitals and communities, on the antibiotic resistance profile and virulence of strains, and on the risk factors associated with infection. These data help clinicians to provide appropriate empiric treatment of infections circulating in their region, leading to improved patient outcomes.

While information on MRSA epidemiology in Latin America is growing, significant gaps exist in the available data, especially in local areas where fewer resources are available for characterizing and reporting MRSA strains. Here, we describe current knowledge of healthcare- and community-associated MRSA epidemiology in the region, and provide recommendations for future development of surveillance systems with a view to providing robust data at regional, national and local levels.
\end{abstract}

Keywords: MRSA, epidemiology, surveillance, Latin America, resistance.

\section{INTRODUCTION}

The epidemiology of methicillin-resistant Staphylococcus aureus (MRSA) is constantly changing, and both circulating clones and their antibiotic resistance profiles vary considerably throughout regions and countries. ${ }^{1,2}$ Appropriate empiric treatment of infections, based on knowledge of local circulating pathogens, is known to lead to better patient outcomes. ${ }^{3,4}$ Therefore, epidemiologic information gathered through ongoing surveillance is essential to support clinicians and infection control committees in their efforts to prevent and treat infection.

Regular surveillance for MRSA in hospital settings in the USA and Europe has been organized since the late 1980s and early 1990s. Through surveillance measures, these regions documented an increasing proportion of MRSA infections, with recent reports of over $50 \%$ of $S$. aureus isolates showing resistance to methicillin in some areas. ${ }^{5-8}$ Significantly, countries with strict infection control practices, such as The Netherlands and countries in the Scandinavian region, have maintained low rates of MRSA infection, even in hospitals.
In Latin America, awareness of the dangers posed by growing antimicrobial resistance motivated the first meeting of the Pan-American Conference on Antimicrobial Resistance in 1998 in Caraballeda, Venezuela. ${ }^{9}$ Following this meeting, a surveillance network was organized to monitor bacterial resistance across the region under the leadership of the Pan-American Health Organization (PAHO). Data quality is a central consideration in developing a reliable surveillance system for MRSA, and individual surveillance centers across Latin America are admitted to the network based on meeting appropriate levels of quality control, standardization and regular data reporting. These laboratories are supported by national and regional reference laboratories. A number of other surveillance studies are active in the region, including several run by pharmaceutical companies such as Bristol Myers Squibb (SENTRY), Wyeth (TEST), and Pfizer (RESISTNET and ZAAPS).

Despite these efforts, resources for monitoring the changing epidemiology of MRSA remain limited, and the true nature and extent of MRSA infections in the region are not well understood.
Authors

Carlos Mejía ${ }^{1}$ Jeannete Zurita ${ }^{2}$ Manuel GuzmánBlanco $^{3}$

on behalf of the Latin American Working

Group on Gram

Positive Resistance

${ }^{1}$ Hospital Roosevelt, Guatemala City, Guatemala.

${ }^{2}$ Hospital Vozandes, Quito, Ecuador. ${ }^{3}$ Centro Médico de Caracas, Caracas, Venezuela.
Correspondence to: Carlos Mejía Infectious Diseases Division Hospital Roosevelt Calz Roosevelt Z-11 Guatemala City, Guatemala Phone: +502-244401086 Fax: +502-24710341 E-mail: mejia villatoro@hotmail. com 
Typically, only a few large hospitals with facilities available to perform microbiological surveillance are able to contribute data. In contrast, much of the population is served by small community healthcare centers without the resources to collect such information. Wider-reaching and coordinated programs to provide regular surveillance reports are needed to support clinicians and infection control committees faced with the challenges of treating and preventing infections due to MRSA. Only by emphasizing the collection of quality data at local levels will we be able to make better clinical decisions.

\section{SURVEILLANCE OF S. AUREUS RESISTANCE}

The overall goal of surveillance in public health is to provide information to decrease morbidity and mortality, and to improve health. This is achieved through ongoing systematic collection, analysis, interpretation and dissemination of data regarding a public health-related event. A surveillance system for MRSA could range from a simple system, in which data are collected from a single hospital, to a complex electronic system that receives and integrates data from multiple sources. ${ }^{10}$ Regardless of the form of data collection, the success of standardized surveillance in countries and regions depends on correct diagnosis of MRSA and identification of specific antimicrobial resistance patterns. Facilities must use appropriate quality standards to achieve these goals successfully, since decisions and recommendations for treatment can be based directly on laboratory results.

Surveillance of MRSA infections is important in both healthcare and community settings due to the continuously changing epidemiologic profile of MRSA. Although traditionally a nosocomial pathogen that infected those patients with known risk factors, ${ }^{11}$ the emergence of cases in the community setting has led to a classification of MRSA strains as either healthcare-associated MRSA (HA-MRSA) or community-associated MRSA (CA-MRSA). ${ }^{1,12-15}$ Healthcare- and community-associated MRSA have differing epidemiologic, clinical, therapeutic, microbiologic and genetic characteristics, ${ }^{16}$ and this has clear implications for their clinical management.

A complicating factor in interpreting epidemiological data comes from the use of different terms to describe MRSA appearing in hospital and community settings. Hospital-acquired MRSA and community-acquired MRSA have sometimes been used synonymously with the terms HAMRSA and CA-MRSA. However, some infections acquired in hospitals may be derived from CA-MRSA strains, and infections acquired in the community may carry healthcareassociated risk factors. ${ }^{17}$ Recent expert guidance proposes that the terms 'hospital-acquired' and 'community-acquired' MRSA should be used to refer to the location of exposure to MRSA, whereas specific MRSA strains should be defined as
HA-MRSA or CA-MRSA, depending on their microbiologic and genetic characteristics. ${ }^{18}$

\section{MRSA IN HOSPITAL SETTINGS IN LATIN AMERICA}

MRSA has become an endemic hospital pathogen in many countries. The US Centers for Disease Control and Prevention (CDC) report that MRSA infections now account for $63 \%$ of staphylococcal infections in the USA, after increasing from $2 \%$ in 1974 and $22 \%$ in $1995 .{ }^{19}$ In the Tigecycline Evaluation and Surveillance Trial (T.E.S.T.), in which data were collected from 33 centers in 11 Latin American countries (Argentina, Brazil, Chile, Colombia, Guatemala, Honduras, Jamaica, Mexico, Panama, Puerto Rico and Venezuela), the overall prevalence of MRSA (including HA- and CA-MRSA strains) among S. aureus isolates was $48.3 \%$ in 2004-2007. ${ }^{20}$ The SENTRY Antimicrobial Surveillance Program in Latin America revealed an increase in the prevalence of MRSA among staphylococcal infections in medical centers from $33.8 \%$ in 1997 to $40.2 \%$ in $2006,{ }^{21}$ although these data are heavily weighted towards specific countries, with $41 \%$ of MRSA strains collected coming from Brazil. A number of other studies report nosocomial MRSA prevalence within Latin American countries, and these data point to differences in the pattern of resistance across the region (see Table $1^{22-35}$ ). In a recent study, the prevalence of MRSA among S. aureus isolates from tertiary hospitals in Colombia, Ecuador, Peru, and Venezuela was found to be $45 \%, 28 \%, 62 \%$ and $26 \%$, respectively. ${ }^{36}$

Hospitalization, residence in long-term care facilities, surgery, hemodialysis, and contact with a person who has an MRSA infection, are all known risk factors for exposure to MRSA. ${ }^{1,16}$ MRSA infections were first reported in hospitals with high levels of oxacillin or methicillin use, and nosocomial MRSA now tends to be multidrug resistant. Healthcare-acquired MRSA is typically defined by an MRSA infection that occurs more than 48 hours following exposure to a healthcare setting, ${ }^{16}$ although a precise designation of an infecting strain is only available through diagnostic testing.

\section{MRSA IN THE COMMUNITY IN LATIN AMERICA}

The earliest report of MRSA acquired in a community setting in Latin America came from a hospital in Uruguay in 2001. Galiana and colleagues reported infections in four children without traditional risk factors for a nosocomial MRSA infection. ${ }^{37}$ Ribeiro and colleagues also provided an early report of CA-MRSA, where they described three strains isolated from patients with septic arthritis or skin and softtissue infections (SSTIs) between 2002 and 2003. ${ }^{38}$

A report of a large outbreak of CA-MRSA in Montevideo, Uruguay, suggests that CA-MRSA is a growing problem in Latin America. Between January 2002 and October 2003, 
Table 1. Prevalence of healthcare-acquired MRSA in Latin American countries ${ }^{22-35}$

\begin{tabular}{|c|c|c|c|}
\hline \multicolumn{4}{|c|}{ MRSA prevalence in nosocomial S. aureus isolates (\%) } \\
\hline \multirow{2}{*}{ Country } & \multicolumn{2}{|c|}{ International studies } & \multirow{2}{*}{ Regional studies } \\
\hline & PAHO $2004^{22}$ & PAAID $2006^{23}$ & \\
\hline Argentina & $42 \%(\mathrm{n}=5,851)$ & $51 \%$ & 2005: $57 \%(n=235)^{24}$ \\
\hline Bolivia & $36 \%(n=1,167)$ & $55 \%$ & - \\
\hline Brazil & - & $54 \%$ & 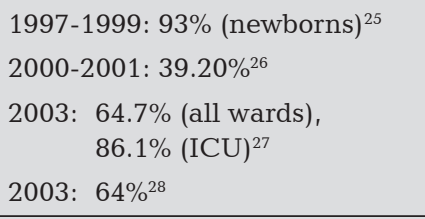 \\
\hline Chile & $80 \%(n=246)$ & $29 \%$ & $\begin{array}{l}\text { 2004-2005: } 53-58 \%^{29} \\
\text { 2006: } 33 \%^{30}\end{array}$ \\
\hline Colombia & $47 \%(\mathrm{n}=4,214)$ & - & $\begin{array}{l}\text { 2001: } 38 \% \\
\text { 2002: } 46 \% \\
\text { 2003: } 45 \% \\
\text { 2004: } 45 \% \\
\text { 2005: } 38 \% \\
\text { 2006: } 34 \%^{31}\end{array}$ \\
\hline Costa Rica & $58 \%(\mathrm{n}=674)$ & - & - \\
\hline Cuba & $6 \%(n=80)$ & - & - \\
\hline Ecuador & $25 \%(\mathrm{n}=1,363)$ & $25 \%$ & - \\
\hline Guatemala & $64 \%(\mathrm{n}=1,483)$ & - & - \\
\hline Honduras & $12 \%(\mathrm{n}=393)$ & - & - \\
\hline Mexico & $52 \%(\mathrm{n}=497)$ & $32 \%$ & $\begin{array}{l}\text { 2008: TEST study, prevalence of } \\
\text { MRSA of } 48 \%{ }^{32}\end{array}$ \\
\hline Nicaragua & $20 \%(\mathrm{n}=296)$ & - & - \\
\hline Panama & - & $28 \%$ & - \\
\hline Paraguay & $44 \%(\mathrm{n}=980)$ & $30 \%$ & - \\
\hline Peru & $80 \%(\mathrm{n}=1,407)$ & - & $\begin{array}{l}\text { 2002: } 85 \%^{33} \\
\text { 2003-2007: } 73.5 \%^{34}\end{array}$ \\
\hline Uruguay & $59 \%(\mathrm{n}=1,431)$ & $24 \%$ & - \\
\hline Venezuela & $25 \%(n=2,114)$ & $27 \%$ & 2005: $36.4 \%{ }^{35}$ \\
\hline
\end{tabular}

more than 1,000 patients from a jail and the community were affected by this outbreak, resulting in 12 deaths. Furthermore, the number of cases increased substantially over a subsequent 22 -month period..$^{39}$ SSTIs were the most common infection, accounting for over $65 \%$ of the cases, but severe cases of pneumonia were also reported, resulting in four deaths.

MRSA has since been identified as a cause of community-acquired infections throughout Latin America, although published data are limited to only a few countries and a few sites within those countries (Table $2^{24,31,33,35,40-44}$ ). The proportion of MRSA infections caused by CA-MRSA clones differs across the region. In a recent study, 74\% of MRSA isolates in Ecuador were found to be caused by clones with genotypic characteristics of CA-MRSA, whereas no CAMRSA clones were observed among MRSA isolates from
Peru. ${ }^{36}$ Surveillance of MRSA infections in the community, whether invasive or SSTIs, is important not only at the level of large hospitals, but also in small community hospitals and ambulatory clinics.

\section{S. AUREUS WITH REDUCED SUSCEPTIBILITY TO VANCOMYCIN}

Vancomycin and other glycopeptide antibiotics, such as teicoplanin, are commonly used to treat MRSA infections. However, reports of staphylococci with reduced susceptibility to vancomycin have begun to emerge worldwide, ${ }^{45}$ including in Latin America. ${ }^{46,47}$ The CDC defines S. aureus as having reduced susceptibility to vancomycin when the minimum inhibitory concentration (MIC) is $4 \mu \mathrm{g} / \mathrm{mL}$ or higher (intermediate susceptibility $4-8 \mu \mathrm{g} / \mathrm{mL}$, resistance $\geq 16 \mu \mathrm{g} / \mathrm{mL}){ }_{.}^{48-50}$ 
Table 2. Prevalence of community-acquired MRSA in Latin American countries ${ }^{24,31,33,35,40-44}$

\begin{tabular}{|c|c|c|c|c|}
\hline Country & Year of study & Prevalence $^{*}$ & $\begin{array}{l}\text { Nature of infection } \\
\text { (if described) }\end{array}$ & Ref. \\
\hline Peru & 2002 & $27 \%$ & - & 33 \\
\hline \multirow[t]{2}{*}{ Colombia } & 2006 & - & $\begin{array}{l}2 \text { cases of SSTI caused } \\
\text { by CA-MRSA strains }\end{array}$ & 40 \\
\hline & 2001-2006 & Increase from $1 \%$ to $5.4 \%$ & - & 31 \\
\hline \multirow[t]{2}{*}{ Venezuela } & 2005 & $12.4 \%$ & - & 35 \\
\hline & 2002-2003 & $16.7 \%$ & SSTI & 41 \\
\hline Chile & 2006-2007 & N/A & $\begin{array}{l}5 \text { cases: } 4 \text { with SSTI, } \\
1 \text { with SSTI and } \\
\text { pneumonia }\end{array}$ & 42 \\
\hline \multirow[t]{3}{*}{ Argentina } & 2005 & $\begin{array}{l}13 \% \text { (adult) } \\
33 \% \text { (pediatric) }\end{array}$ & $\begin{array}{l}\text { SSTI }(90 \%) \\
\text { Bone and joint }(5 \%) \\
\text { Respiratory tract }(5 \%)\end{array}$ & 24 \\
\hline & 2005-2006 & N/A & $\begin{array}{l}\text { Bacteremia }(4 / 33 \\
\text { patients, all under } 12) \\
\text { SSTI (all patients over } \\
12)\end{array}$ & 43 \\
\hline & 2006-2007 & $62 \%$ (pediatric) & $\begin{array}{l}\text { SSTI }(62 \%) \\
\text { Invasive infections (38\%) }\end{array}$ & 44 \\
\hline
\end{tabular}

${ }^{*}$ Prevalence of community-acquired MRSA among community-acquired S. aureus isolates.

Despite this definition, recent reports indicate that patients infected with MRSA strains with a MIC $>1 \mu \mathrm{g} / \mathrm{mL}$ have a poor response to the usual prescribed doses of vancomycin. ${ }^{51}$

The earliest reports of $S$. aureus infections with reduced susceptibility to vancomycin were in patients with previous MRSA infections and exposure to multiple and prolonged courses of vancomycin. ${ }^{45,52}$ The first report of MRSA with reduced susceptibility to vancomycin in Latin America was in Brazil in 2001. ${ }^{46}$ Oliveira and colleagues screened 140 nosocomial isolates of MRSA and found five with a vancomycin MIC of $8 \mu \mathrm{g} / \mathrm{mL}$, demonstrating reduced susceptibility. In the patients with infections due to these strains of MRSA, four patients had been treated with vancomycin for over 30 days, although one patient received only a 7-day course. Isolates with reduced vancomycin susceptibility have also been identified in the community. ${ }^{46,47}$ However, MRSA strains with reduced susceptibility to vancomycin do not appear to be increasing in the region. In a 10-year report from the SENTRY Antimicrobial Surveillance Program (1997-2006), which showed resistance to most antibiotics increasing across Latin America, the percentage of MRSA with vancomycin MIC $\geq 1 \mu \mathrm{g} / \mathrm{mL}$ decreased from $96.6 \%$ in $1999-2001$ to $92.3 \%$ in $2002-2006 .{ }^{21}$ Despite this apparent 'reversecreep', the potential importance of these strains requires that they still be included in future surveillance programs.

\section{S. AUREUS WITH INDUCIBLE MLS $S_{B}$ RESISTANCE}

Antibiotics belonging to the macrolide-lincosamide-streptogramin $\mathrm{B}\left(\mathrm{MLS}_{\mathrm{B}}\right)$ family are commonly used to treat staphylococcal infections, including $S$. aureus. ${ }^{53}$ CA-MRSA clones are usually susceptible to the lincosamide antibiotic clindamycin, which penetrates easily into the skin, making it particularly useful for the treatment of SSTIs.

Clindamycin kills bacteria by inhibiting ribosomal translocation and is active even in the presence of a high bacterial burden at the site of infection. ${ }^{54,55}$ However, MRSA strains have emerged containing a ribosomal target modification, which confers $\mathrm{MLS}_{\mathrm{B}}$-inducible resistance to clindamycin. In the presence of low levels of erythromycin, clindamycin resistance is induced, which can lead to therapeutic failure.

The prevalence of $\mathrm{MLS}_{\mathrm{B}}$-inducible resistance among MRSA clones is not widely reported. In a Brazilian study, $11.3 \%$ of S. aureus isolates were shown to have this pheno- 
type ${ }^{56}$ whereas $24.4 \%$ of MRSA isolates tested positive for $\mathrm{MLS}_{\mathrm{B}}$-inducible resistance in a Turkish study. ${ }^{57}$

Surveillance techniques using standard susceptibility methods are liable to overlook clones with inducible resistance to clindamycin, but a double-disc diffusion test is now available, using clindamycin and erythromycin discs in close proximity, in order to observe this phenotype. ${ }^{53,58}$ In surveillance situations, positive results from double-disc diffusion tests should be disseminated quickly in order to allow clinicians to avoid the use of clindamycin in these patients.

\section{MRSA MOLECULAR SURVEILLANCE}

Molecular techniques, such as PCR, DNA sequencing and hybridization techniques, offer the potential for gathering a new level of detail in MRSA surveillance. For example, molecular surveillance provides a means to differentiate HAMRSA from CA-MRSA, and allows the description of genetic variants in relation to clinical syndromes. Such findings can guide the implementation of preventive and therapeutic measures, improve patient management and reduce the impact of MRSA infections in both community and hospital settings. Rapid MRSA detection using molecular techniques, such as real-time PCR, is expected to have a significant clinical impact on patient outcome and on the costs for isolation and treatment.

Molecular techniques are fundamental to a successful surveillance system, especially within reference facilities, and their introduction into regional laboratories would provide opportunities for quick and reliable identification of MRSA isolates at a local level. However, they also require considerable resources, including expensive instrumentation and skilled technicians. Consequently, the use of molecular approaches is limited in some Latin American countries, especially in less developed regions where resources are limited.

\section{RECOMMENDATIONS FOR LOCAL, NATIONAL AND REGIONAL SURVEILLANCE OF MRSA}

In Latin America, MRSA surveillance conducted by Emerging Infections Programs or Hospital Infection Programs must have two principal goals:

1) To monitor and report the incidence and epidemiologic characteristics of healthcare-acquired and community-acquired MRSA infections.

2) To assess and report the molecular epidemiologic patterns of HA- and CA-MRSA.

Implementation of a robust surveillance system is dependent on the use of appropriate monitoring and reporting procedures. Isolates may be obtained from patients receiving routine clinical care for suspected infections, or from a broader screening strategy monitoring asymptomatic colonization by active surveillance. ${ }^{59}$ Microbiologic data from patients receiving routine clinical care can be used to assess the incidence of infection in certain populations, the clinical impact of infection and the success of prevention strategies. An active surveillance program may be used for early detection and monitoring of MRSA in high-risk patient populations, ${ }^{60}$ with the nares being a reliable source of cultures to identify MRSA. ${ }^{60}$

Successful monitoring of MRSA requires data collection to be both extensive and accurate. In this regard, robust quality control procedures are of high importance, and reference laboratories are needed to provide definitive results. Susceptibility testing should be incorporated into surveillance systems, including MIC determination for vancomycin, and detection of inducible clindamycin resistance. Rapid detection methods for MRSA, such as chromogenic agar and real-time PCR-based tests, may reduce the time to positive diagnosis by 2-3 days. Automated software, such as WHONET, can be used for efficient data collection and analysis.

Appropriate reporting procedures should include regular surveillance updates through local, regional and national publications, alongside early warning systems to inform clinicians, pharmacists and hospital directors of local outbreaks in their regions. Internet updates, including clinical data and demographic information, are useful in this regard, as they are both rapid and wide-reaching. Within hospitals, the Clinical and Laboratory Standards Institute (CLSI) recommends preparation of antimicrobial susceptibility reports that are specific to the facility, and provides specific recommendations on how to prepare these reports and the key information to be included within them. ${ }^{61}$ Reports should be monitored routinely for evidence of developing resistance patterns. ${ }^{59}$ In addition to local dissemination of surveillance information, communication between surveillance networks in Latin America is vital if information is to be spread quickly across the region.

An important aspect of developing successful surveillance systems is the appropriate training of personnel, from microbiologists involved in monitoring MRSA to clinicians providing patient care. Infection control committees should be charged with ensuring the use of monitoring techniques that are appropriate to the local setting, and with providing updated information to inform clinicians of the evolving epidemiology in their region.

In summary, surveillance is an important tool that assists in the implementation of different preventive and therapeutic measures to combat MRSA infections in the community and in hospitals. With accurate surveillance information, clinicians in Latin America would be able to effect appropriate antibiotic treatment for MRSA infections, having regard for likely antibiotic-resistance profiles and community- or healthcare-associated characteristics of strains within their region. 


\section{IMPLICATIONS FOR CLINICAL PRACTICE}

- Surveillance systems monitoring the spread and divergence of MRSA strains are critical if preventive and therapeutic measures targeting MRSA infection are to be employed optimally.

- Robust surveillance requires extensive and accurate data collection, including data from both clinical isolates and active surveillance programs.

- Reporting of surveillance information should include antimicrobial susceptibility reports from individual hospitals, regional and national summary publications, and early warning systems to inform of local outbreaks.

- Communication between surveillance

networks is important to facilitate the spread of information across the region.

- Infection control committees should oversee the use of appropriate monitoring techniques and provide structures for education of healthcare personnel on local epidemiology of infections.

\section{ACKNOWLEDGEMENTS}

\section{Financial support}

Pfizer Inc., New York, NY, USA, provided support for meetings of the Latin American Working Group on Gram Positive Resistance. Pfizer Inc. had no involvement in the collection, analysis and interpretation of data, in the writing of the manuscripts, or in the decision to submit the articles for publication.

\section{Manuscript preparation}

The support provided by Choice Pharma (Hitchin, UK), funded by Pfizer Inc., consisted of manuscript formatting and writing assistance.

\section{DISCLOSURES}

C. Mejía: Advisory Board member for Pfizer and Abbott; consultant for Pfizer; received funding from Tibotec for HIV research, from Avexa for studies in HIV treatment, and from Merck for participation in the SMART study.

J. Zurita: Advisory Board member and consultant for Pfizer; received research grant from Wyeth.

M. Guzmán-Blanco: Advisory Board member for Pfizer, Merck and BD; consultant for Pfizer, Wyeth and Janssen; received research funding from Wyeth and Merck.

\section{REFERENCES}

1. Guzmán-Blanco M, Mejía C, Isturiz R et al. Epidemiology of methicillin-resistant Staphylococcus aureus (MRSA) in Latin America. Int J Antimicrob Agents. 2009; 34(4):304-8.

2. Rodriguez-Noriega E, Seas C, Guzmán-Blanco M et al. Evolution of methicillin-resistant Staphylococcus aureus clones in Latin America. Int J Infect Dis. 2010; 14:e560-6.
3. Leibovici L, Shraga I, Drucker M et al. The benefit of appropriate empirical antibiotic treatment in patients with bloodstream infection. J Intern Med. 1998; 244(5):379-86.

4. Kollef MH. Inadequate Antimicrobial Treatment: An Important Determinant of Outcome for Hospitalized Patients. Clin Infect Dis. 2000; 31(Suppl 4):S131-8.

5. Klevens RM, Edwards JR, Tenover FC et al. Changes in the epidemiology of methicillin-resistant Staphylococcus aureus in intensive care units in US hospitals, 1992-2003. Clin Infect Dis. 2006; 42(3):389-91.

6. Moran GJ, Krishnadasan A, Gorwitz RJ et al. Methicillin-resistant $S$. aureus infections among patients in the emergency department. N Engl J Med. 2006; 355(7):666-74.

7. ECDC. European Antimicrobial Resistance Surveillance System Annual Report 2007. (http://www.rivm.nl/earss/Images/ EARSS\%202007_FINAL_tcm61-55933.pdf) Accessed 18 October 2009.

8. Meyer E, Schwab F, Gastmeier P et al. Methicillin-resistant Staphylococcus aureus in German intensive care units during 2000-2003: data from Project SARI (Surveillance of Antimicrobial Use and Antimicrobial Resistance in Intensive Care Units). Infect Control Hosp Epidemiol. 2006; 27(2):146-54.

9. Pan American Conference on Antimicrobial Resistance in the Americas. Epidemiol Bull. 1999; 20(2):6-7.

10. CDC. MMWR Updated Guidelines for Evaluating Public Health Surveillance Systems: Recommendations from the Guidelines Working Group July 27, 2001. (http://www.cdc. gov/mmwr/preview/mmwrhtml/rr5013al.htm) Accessed October 2009.

11. Naimi TS, LeDell KH, Como-Sabetti K et al. Comparison of community- and health care-associated methicillin-resistant Staphylococcus aureus infection. JAMA. 2003; 290(22):2976-84.

12. Turnidge JD, Bell JM. Methicillin-resistant Staphylococcal aureus evolution in Australia over 35 years. Microb Drug Resist. 2000; 6(3):223-9.

13. Gorwitz RJ. Understanding the success of methicillin-resistant Staphylococcus aureus strains causing epidemic disease in the community. J Infect Dis. 2008; 197(2):179-82.

14. Wang R, Braughton KR, Kretschmer D et al. Identification of novel cytolytic peptides as key virulence determinants for community-associated MRSA. Nat Med. 2007; 13(12):1510-4.

15. Mulvey MR, MacDougall L, Cholin B et al. Community-associated methicillin-resistant Staphylococcus aureus, Canada. Emerg Infect Dis. 2005; 11(6):844-50.

16. David MZ, Glikman D, Crawford SE et al. What is community-associated methicillin-resistant Staphylococcus aureus? J Infect Dis. 2008; 197(9):1235-43.

17. Zetola N, Francis JS, Nuermberger EL, Bishai WR. Community-acquired meticillin-resistant Staphylococcus aureus: an emerging threat. Lancet Infect Dis. 2005; 5(5):275-86.

18. Flynn N, Cohen SH. The continuing saga of MRSA. J Infect Dis. 2008; 197(9):1217-9.

19. CDC. MRSA in healthcare settings. Department of Health and Human Services 2007. (http://www.cdc.gov/ncidod/dhqp/ ar_MRSA_spotlight_2006.html) Accessed 10 November 2009.

20. Rossi F, Garcia P, Ronzon B et al. Rates of antimicrobial resistance in Latin America (2004-2007) and in vitro activity of the glycylcycline tigecycline and of other antibiotics. Braz J Infect Dis. 2008; 12(5):405-15.

21. Picao R, Sader H, Jones R et al. Analysis of resistance and vancomycin "reverse creep" in Latin American Staphylococcus aureus: ten-year report of the SENTRY Antimicrobial Surveillance Program (1997-2006). Clin Microbiol Infect. 2008; 14:S173. 
22. Pan American Health Organisation. Annual report of the Monitoring/Surveillance Network for Resistance to Antibiotics, 2004. (http://www.paho.org/English/AD/DPC/CD/amr2004.htm) Accessed 22 November 2009.

23. Pan-American Association of Infectious Diseases. Results of the 7th Survey of the Comitê de Resistência in Antimicrobials of API. Rev Panam de Infect. 2006; 8:48-51.

24. Sola C, Saka HA, Vindel A, Bocco JL. Emergence and Dissemination of a Community-Associated Methicillin-Resistant Panton-Valentine Leucocidin-Positive Staphylococcus aureus Clone Sharing the Sequence Type 5 Lineage with the Most Prevalent Nosocomial Clone in the Same Region of Argentina. J Clin Microbiol. 2008; 46(5):1826-31.

25. Loureiro MM, Graces B, Quadra M et al. Study of multidrug resistant microorganisms isolated from blood cultures of hospitalized newborns in Rio de Janeiro city, Brazil. Braz J Microbiol. 2002; 33:73-8.

26. Ribas RM, Freitas C, Gontijo Filho PP. Nosocomial bloodstream infections: organisms, risk factors and resistant phenotypes in the Brazilian University Hospital. Braz J Infect Dis. 2007; 11(3):351-4.

27. Melo DO, Sasaki M, Grinbaum RS. Vancomycin use in a hospital with high prevalence of methicillin-resistant Staphylococcus aureus: comparison with Hospital Infection Control Practices Advisory Committe Guidelines (HICPAC). Braz J Infect Dis. 2007; 11(1):53-6.

28. Lisboa T, Faria M, Hoher J et al. The prevalence of nosocomial infection in Intensive Care Units in the State of Rio Grande do Sul. Rev Bras Ter Intensiva 2007; 19(4):414-20.

29. Ruiz CM, Guerrero PJ, Romero PC. Etiology of ventilator-associated pneumonia in a university hospital. Association with comorbidity, previous use of antibiotics and mortality. Rev Chilena Infectol. 2007; 24:131-6.

30. Otth RL, Wilson SM, Bustamante HN et al. Antimicrobial susceptibility and resistance patterns of Staphylococcus aureus isolated from patients and carriers in Valdivia city, Chile. Rev Chilena Infectol. 2008; 25:175-8.

31. Buitrago G, Cortes JA, Castillo JS et al. Methicillin-resistant Staphylococcus aureus. Community-acquired phenotype spread in hospitals in Bogota, Colombia. Clin Microbiol Infect. 2008; 14:S411.

32. Ponce de Leon A, Amabile-Cuevas CF, Benitez A. In vitro activity of tigecycline and other antimicrobial drugs against selected pathogens isolated in Mexico. Clin Microbiol Infect. 2008; 14:S611.

33. Seas C, Hernandez K, Ramos R et al. Oxacillin-resistant and multidrug-resistant Staphylococcus aureus in Lima, Peru. Infect Control Hosp Epidemiol. 2006; 27(2):198-200.

34. Cuellar LE, Fernandez-Maldonado E, Rosenthal VD et al. Device-associated infection rates and mortality in intensive care units of Peruvian hospitals: findings of the International Nosocomial Infection Control Consortium. Rev Panam Salud Publica. 2008; 24(1):16-24.

35. Pfizer Venezuela S.A. Venezuelan program of surveillance of bacterial resistance to antobiotics; 1998-2006. (http://www. provenra.org) Accessed 17 May 2010.

36. Reyes J, Rincon S, Diaz L et al. Dissemination of methicillinresistant Staphylococcus aureus USA300 sequence type 8 lineage in Latin America. Clin Infect Dis. 2009; 49(12):1861-7.

37. Galiana VA. Infecciones por Staphylococcus aureus adquiridos en la comunidad. Arch Pediatr Urug 2003; 74:26-9.
38. Ribeiro A, Dias C, Silva-Carvalho MC et al. First report of infection with community-acquired methicillin-resistant Staphylococcus aureus in South America. J Clin Microbiol. 2005; 43(4):1985-8.

39. Ma XX, Galiana A, Pedreira W et al. Community-acquired methicillin-resistant Staphylococcus aureus, Uruguay. Emerg Infect Dis. 2005; 11(6):973-6.

40. Alvarez CA, Barrientes OJ, Leal AL et al. Community-associated methicillin-resistant Staphylococcus aureus, Colombia. Emerg Infect Dis. 2006; 12(12):2000-1.

41. Guzmán-Lista MDC, Lozada-Oca RA. Detection of methicillin-resistant Staphylococcus aureus isolated from patients with nosocomials and community-acquired infections. Rev Soc Ven Microbiol. 2007; 27(1):349-63.

42. Noriega LM, Gonzalez P, Hormazabal JC et al. Community acquired infections with methicillin resistant strains of Staphylococcus aureus: report of five cases. Rev Med Chil. 2008; 136(7):885-91.

43. Palombarani S, Gardella N, Tuduri A et al. Community-acquired methicillin-resistant Staphylococcus aureus infections in a hospital for acute diseases. Rev Argent Microbiol. 2007; 39(3):151-5.

44. Paganini H, Della Latta MP, Muller Opet B et al. Community-acquired methicillin-resistant Staphylococcus aureus infections in children: multicenter trial. Arch Argent Pediatr. 2008; 106(5):397-403.

45. Hiramatsu K, Hanaki H, Ino T et al. Methicillin-resistant Staphylococcus aureus clinical strain with reduced vancomycin susceptibility. J Antimicrob Chemother. 1997; 40(1):135-6.

46. Oliveira GA, Dell'Aquila AM, Masiero RL et al. Isolation in Brazil of nosocomial Staphylococcus aureus with reduced susceptibility to vancomycin. Infect Control Hosp Epidemiol. 2001; 22(7):443-8.

47. Palazzo IC, Araujo ML, Darini AL. First report of vancomycinresistant staphylococci isolated from healthy carriers in Brazil. J Clin Microbiol. 2005; 43(1):179-85.

48. Hageman JC, Patel J, Carey RC et al. Investigation and control of vancomycin-intermediate and -resistant Staphylococcus aureus: A Guide for Health Departments and Infection Control Personnel. 2006. (http://www.cdc.gov/ncidod/dhqp/pdf/ar/ visa_vrsa_guide.pdf) Accessed 10 November 2009.

49. CLSI. Performance Standards for Antimicrobial Susceptibility Testing; Nineteenth Informational Supplement (M100-S19). 2009. Clinical and Laboratory Standards Institute. Wayne, PA. (http://www.clsi.org/source/orders/free/m100-s19.pdf) Accessed 23 November 2009.

50. Tenover FC, Moellering RC, Jr. The rationale for revising the Clinical and Laboratory Standards Institute vancomycin minimal inhibitory concentration interpretive criteria for Staphylococcus aureus. Clin Infect Dis. 2007; 44(9):1208-15.

51. Sakoulas G, Moise-Broder PA, Schentag J et al. Relationship of MIC and bactericidal activity to efficacy of vancomycin for treatment of methicillin-resistant Staphylococcus aureus bacteremia. J Clin Microbiol. 2004; 42(6):2398-402.

52. Smith TL, Pearson ML, Wilcox KR et al. Emergence of vancomycin resistance in Staphylococcus aureus. Glycopeptide-Intermediate Staphylococcus aureus Working Group. N Engl J Med. 1999; 340(7):493-501.

53. Fiebelkorn KR, Crawford SA, McElmeel ML, Jorgensen JH. Practical disk diffusion method for detection of inducible clindamycin resistance in Staphylococcus aureus and coagulasenegative staphylococci. J Clin Microbiol. 2003; 41(10):4740-4. 
54. Stevens DL, Gibbons AE, Bergstrom R, Winn V. The Eagle effect revisited: efficacy of clindamycin, erythromycin, and penicillin in the treatment of streptococcal myositis. J Infect Dis. 1988; 158(1):23-8.

55. Martinez-Aguilar G, Hammerman WA, Mason EO, Jr., Kaplan SL. Clindamycin treatment of invasive infections caused by community-acquired, methicillin-resistant and methicillinsusceptible Staphylococcus aureus in children. Pediatr Infect Dis J. 2003; 22(7):593-8.

56. van der Heijden IM, Sinto S, Oplustil SC, Mendes C. Occurrence of MLS resistance in staphylococcal and streptococcol clinical isolates. Abstract A-86. Presented at the 101st General Meeting of the American Society for Microbiology. Washington, DC, 2001.

57. Yilmaz G, Aydin K, Iskender S et al. Detection and prevalence of inducible clindamycin resistance in staphylococci. J Med Microbiol. 2007; 56(Pt 3):342-5.
58. Lewis JS, 2nd, Jorgensen JH. Inducible clindamycin resistance in Staphylococci: should clinicians and microbiologists be concerned? Clin Infect Dis. 2005; 40(2):280-5.

59. Siegel JD, Rhinehart E, Jackson M, Chiarello L. Management of multidrug-resistant organisms in health care settings, 2006. Am J Infect Control. 2007; 35(10 Suppl 2):S165-93.

60. Manian FA, Senkel D, Zack J, Meyer L. Routine screening for methicillin-resistant Staphylococcus aureus among patients newly admitted to an acute rehabilitation unit. Infect Control Hosp Epidemiol. 2002; 23(9):516-9.

61. CLSI. Analysis and Presentation of Cumulative Antimicrobial Susceptibility Test Data; Approved Guideline-Third Edition (M39-A3) Clinical and Laboratory Standards Institute, Wayne, PA, 2009. 